\title{
Hydrodynamic loading in concomitance with exogenous cytokine stimulation modulates differentiation of bovine mesenchymal stem cells towards osteochondral lineages
}

Stephen M. Goldman ${ }^{1,2}$ and Gilda A. Barabino ${ }^{1,3^{*}}$

\begin{abstract}
Background: Mesenchymal stem cells (MSCs) are viewed as a having significant potential for tissue engineering and regenerative medicine therapies. Clinical implementation of MSCs, however, demands that their preparation be stable and reproducible. Given that environmental and bioprocessing parameters such as substrate stiffness, seeding densities, culture medium composition, and mechanical loading can result in undirected differentiation of the MSC population, the objective of this study was to systematically investigate how hydrodynamic loading influences the differentiation of bone marrow-derived mesenchymal stem cells (MSCs) towards the osteochondral lineages both in the presence and absence of exogenous, inductive factors.

Methods: Expanded bovine MSCs were suspended in $2.5 \%$ agarose, cast in a custom mold, and placed into either static or one of two dynamic culture environments consisting of "high" and "low" magnitude shear conditions. Constructs were supplemented with varying concentrations $(0,1,10,100 \mathrm{ng} / \mathrm{mL})$ of either TGF- $\beta 3$ or BMP-2 throughout cultivation with tissue samples being collected following each week of culture.

Results: In the absence of exogenous supplementation, hydrodynamic loading had little effect on cell phenotype at either magnitude of stimulation. When cultures were supplemented with BMP-2 and TGF- $\beta 3$, MSCs gene expression progressed towards the osteogenic and chondrogenic pathways, respectively. This progression was enhanced by the presence of hydrodynamic loading, particularly under high shear conditions, but may point the chondrogenic cultures down a hypertrophic path toward osteogenesis reminiscent of endochondral ossification if TGF- $\beta 3$ supplementation is insufficient.
\end{abstract}

Conclusions: Moving forward, these results suggest bioprocessing conditions which minimize exposure of chondrogenic cultures to fluid shear stress to avoid undesirable differentiation of the MSC population.

Keywords: Mesenchymal stem cells, Fluid shear stress, Chondrogenesis, Osteogenesis, Bioprocessing, Biomanufacturing

\footnotetext{
* Correspondence: barabino@ccny.cuny.edu

${ }^{1}$ Interdisciplinary Bioengineering Graduate Program, Georgia Institute of

Technology, Atlanta, GA, 30332, USA

${ }^{3}$ Department of Biomedical Engineering, City College of New York, 160

Convent Avenue, New York, NY, 10031, USA

Full list of author information is available at the end of the article
} 


\section{Background}

Due to their limited supply and decreased proliferative capacity, the sole use of autologous chondrocytes and osteoblasts for regenerative medicines is likely unsustainable [1]. Subsequently, mesenchymal stem cells (MSCs) have emerged as a clinically relevant cell source for regenerative medicine, due to their ease of procurement, multipotentiality, high proliferation rate, and ability to be expanded in vitro while maintaining a stable phenotype [2-4]. Directed differentiation of MSCs along various mesenchymal pathways can be achieved by manipulation of the cell culture environment including supplementation of culture medium with soluble morphogens [5-9], modulation of culture substrate stiffness [10], and external forces [11, 12]. Of particular interest are environmental approaches which might increase differentiation efficiency while reducing upstream bioprocessing costs for the purpose of large scale commercial operations.

A predominant challenge of the scaling operations required to process large numbers of cells and/or critically sized tissue constructs is the control of nutrient and waste transport from the cells/tissues during culture. To overcome these issues, a number of bioreactor concepts have been developed to provide the flow of culture media through [13], across [14], and around the constructs $[15,16]$. As a result of the medium exchange, the constructs are concurrently nourished and exposed to hydrodynamic loading. Shear stress is known to cause varied effects on cell populations, including transmembrane ion leakage, as well as physiological and metabolic changes [17]. The presence of fluid shear stress, therefore, is an important environmental factor which may play an important role in the stability or instability of the MSC phenotype in culture. Furthermore, if the magnitude and spatiotemporal presentation of hydrodynamic loading can be controlled, it may represent a novel approach to modulating the efficiency of directed MSC differentiation. The primary objective of this study, therefore, was to determine the effect of uniform shear stress magnitude and duration on MSC gene expression through a panel of key differentiation markers along the osteochondral differentiation pathway. These genes were selected for their importance in orthopedic tissue engineering applications and potential to provide a window into the chondrogenic and osteogenic differentiation processes.

Given the well-documented sensitivity of mature chondrocytes and osteoblasts to the TGF- $\beta$ superfamily [8], a secondary objective of this study was to examine the response of MSCs to varying magnitudes of superficial hydrodynamic shear stress in cultures supplemented with varying concentrations of TGF- $\beta 3$ and BMP-2. Drawing on evidence that both bone and cartilage are mechanosensitive [18, 19] and mechanical stimuli are anabolic $[20,21]$, we hypothesized that hydrodynamic loading would increase the efficiency of MSC differentiation down the desired pathways as revealed through systematic changes in phenotypic markers. The scope of the study was limited to a range of hydrodynamic conditions within the reported interstitial flow regime of bone [22] and cartilage [23] with a view to determining an optimum for lineage specific differentiation. Additionally, the cytokine concentrations were varied by one order of magnitude in either direction from the most ubiquitous supplementation protocols found in the literature concurrently, to determine how hydrodynamic culture might minimize their necessity.

\section{Methods \\ Materials}

Unless specified otherwise, supplies and reagents were purchased from VWR International (West Chester, PA), Sigma (St. Louis, MO) or Invitrogen (Carlsbad, CA). Antibodies were from AbD Serotec (Raleigh, NC) or Abcam (Cambridge, MA).

\section{Experimental design}

To elucidate the role of hydrodynamic loading in MSC differentiation towards the osteochondral lineages, we selected three magnitudes of fluid shear stress $(0,1$, $10 \mathrm{dyn} / \mathrm{cm}^{2}$ ) to be applied in the presence of four levels of exogenous stimulation $(0,1,10,100 \mathrm{ng} / \mathrm{mL})$ for two different cytokines (BMP-2, TGF- $\beta 3$ ) resulting in 12 experimental groups which received some level of both hydrodynamic and exogenous stimuli, three groups which received only TGF- $\beta 3$ stimulation of varying degrees, three groups which received only BMP-2 stimulation of varying degrees, and three unsupplemented groups which received only hydrodynamic stimulation of varying degrees (Additional file 1: Table S1). Samples from each experimental group were collected on a weekly basis for 2 weeks. Additional samples for each group were generated at the start of tissue culture (Week 0), but never subjected to any of the stated experimental conditions in order to generate a baseline for downstream analysis.

\section{Tissue culture}

MSCs isolated and characterized from the limbs three different animals post-mortem (see Additional file 2 Supplemental Methods, Additional file 3: Figure S1, Additional file 4: Figure S2) were mixed with sterile agarose solution such that the final concentration of MSCs in $2.5 \% \mathrm{w} / \mathrm{w}$ agarose solution was 25 million cells/mL. Constructs were then cast into a polydimethylsiloxane [PDMS] mold and cultured either statically $\left(0 \mathrm{dyn} / \mathrm{cm}^{2}\right)$ or loaded in a custom flow chamber (Fig. 1) for dynamic culture at one of two wall shear stress (WSS) conditions: low shear (1 dyn/ $\left.\mathrm{cm}^{2}\right)$ or high shear $\left(10 \mathrm{dyn} / \mathrm{cm}^{2}\right)$. To achieve the variation in shear stress at the wall $\left(\tau_{\text {wall }}\right)$, the channel height $(\mathrm{h})$ 


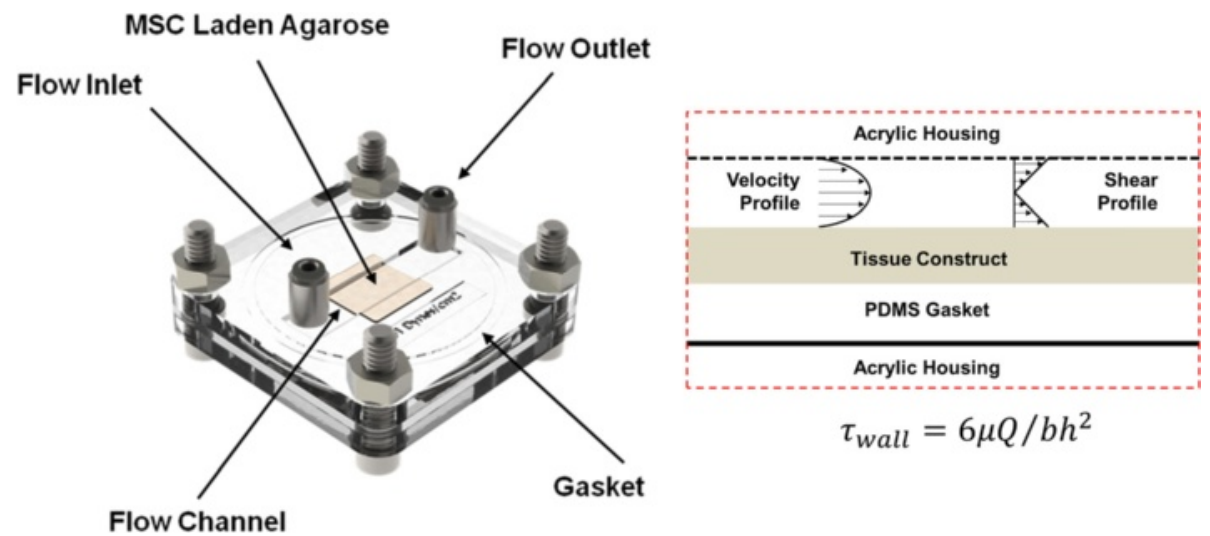

Fig. 1 Tissue constructs were cultivated utilizing a custom built laminar flow chamber (left). Two separate devices with varying channel heights were produced such that parallel cultures of different hydrodynamic loading magnitudes could be simultaneously driven by a single peristaltic pump according to the relationship depicted (right)

was varied between two different chamber designs while the kinematic viscosity $(\mu)$, Volumetric Flow Rate, and the channel width (b) were held constant. This approach allowed multiple flow loops from different experimental groups to be driven simultaneously by a single, multichannel peristaltic pump (Masterflex, Cole Parmer, Vernon Hills, IL). Unsupplemented culture groups received a serum free basal media (high glucose DMEM, 1× PSF, $0.1 \mu \mathrm{M}$ dexamethasone, $50 \mu \mathrm{g} / \mathrm{mL}$ ascorbate 2-phosphate, $40 \mu \mathrm{g} / \mathrm{mL}$ l-proline, $100 \mu \mathrm{g} / \mathrm{mL}$ sodium pyruvate, $1 \times$ insulin-transferrin-selenium [ITS]). All other experimental groups received the serum free basal media supplemented with a prescribed concentration $(1,10$, or $100 \mathrm{ng} / \mathrm{mL}$ ) or either TGF- $\beta 3$ or BMP-2.

\section{mRNA expression}

Real-time polymerase chain reaction (qRT-PCR) was used to quantify region specific gene expression within the constructs. Constructs were fixed in TRIzol, and RNA was isolated from the homogenized cell lysate through a series of rinse, elution, and centrifugation processes. The RNA samples were then reverse transcribed into cDNA using a QuantiTech Rev Transcription kit (Qiagen, Hilden, German) according to the manufacturer's protocol. Gene expression for target mesenchymal lineage markers using custom-designed primers (Additional file 1: Table S2) with quantitative PCR amplification performed on a StepOnePlus ${ }^{\mathrm{Tn}}$ Real-Time PCR System (Applied Biosystems) in the presence of SYBR Green/ROX master mix (Applied Biosystems). To determine fold regulation over Day 0 controls, the raw fluorescence data was processed using LinRegPCR (v12.11; http://www.hartfaalcentrum.nl) with glyceraldehyde-3phosphate dehydrogenase (GAPDH) and $\beta$-Actin (ACTB) serving as the endogenous controls through geometric averaging [24]. Relative expression $(n=3$ per condition and time point) of each target gene was calculated according to Eqs. 1-2, where $N_{0, i}$ represents the initial concentration of the target gene, $N_{q, i}$ represents the concentration of the target gene at the threshold, $E_{i}$ represents the amplification efficiency of the polymerase chain reaction, and $C_{q}$ is the selected threshold value.

$$
\begin{gathered}
N_{0, i}=N_{q, i} / E_{i}^{C_{q}} \\
\text { Fold Change }=\left(\frac{N_{0, i}}{\sqrt{N_{0, G A P D H} N_{0, A C T B}}}\right)_{\text {sample }} /\left(\frac{N_{0, i}}{\sqrt{N_{0, G A P D H} N_{0, A C T B}}}\right)_{\text {control }}
\end{gathered}
$$

Endogenous controls were evaluated for each experimental group to ensure that their expression levels were not significantly altered across time or culture conditions.

\section{Histological analysis}

For histological analysis, constructs were fixed in $10 \%$ buffered formalin, embedded in paraffin and sectioned into $8 \mu \mathrm{m}$ thick sections for the midsubstance of the construct. Sectioned samples were stained with Toluidine blue and Alizarin Red per established protocols. For immunofluorescence, sections were incubated with a citrate buffer heated to $99^{\circ} \mathrm{C}$ for $30 \mathrm{~min}$ to retrieve antigens, and allowed to cool to room temperature. The samples were then incubated in blocking buffer for $30 \mathrm{~min}$ and primary rabbit anti-bovine antibodies (1:100, Abcam, Cambridge, MA) for Collagen types I, II, and X at $4{ }^{\circ} \mathrm{C}$ overnight. Sections were then washed three times in PBS and with DyLight ${ }^{\circ} 594$ goat anti-rabbit secondary antibodies (1:200, Abcam, Cambridge, MA) for one hour at room temperature. Finally, samples were washed and mounted with Vectashield with DAPI and visualized on a Nikon Ti Eclipse inverted fluorescence microscope (Nikon Instruments, Inc., Melville, NY), with representative 
images captured using a CoolSNAP HQ2 CCD camera (Photometrics, Tucson, AZ).

\section{Statistical analysis}

Independent experiments produced construct samples for RT-qPCR and immunohistochemistry $(N=3$ per group). Gene expression is presented as the mean fold change \pm SEM with statistically significant differences defined as $p<0.05$ using two-way ANOVA with Bonferroni post-hoc tests for multiple comparisons.

\section{Results}

Stability of gene expression in unsupplemented cultures In order to control for the effect of hydrodynamic loading on the gene expression profile of MSCs, a round of control experiments was performed to assess the stability of the MSC transcriptome in unsupplemented, static, three dimensional culture over the course of 2 weeks of cultivation (Fig. 2). None of the genes measured exhibited significant regulation over the time course of the experiment with respect to the initial expression profile, indicating three dimensional culture in isolation of other factors was not a significant contributor to differentiation of the MSCs toward the desired lineages and that this culture format represents a suitable control for differentiation studies. This was an important realization, as there is evidence in the literature that subtle changes in culture conditions, such as the transition from monolayer to three-dimensional culture represented here can induce phenotypic changes in stem cell populations [10, 11, 25], particularly as a significant contributor to chondrogenesis [26]. It is important to note, however, that many of the protocols from the prior art depend on pellet culture whereas this study is dependent on the encapsulation of the MSCs in a three dimensional agarose hydrogel. The introduction of the hydrogel material provides additional barriers to communication by cell
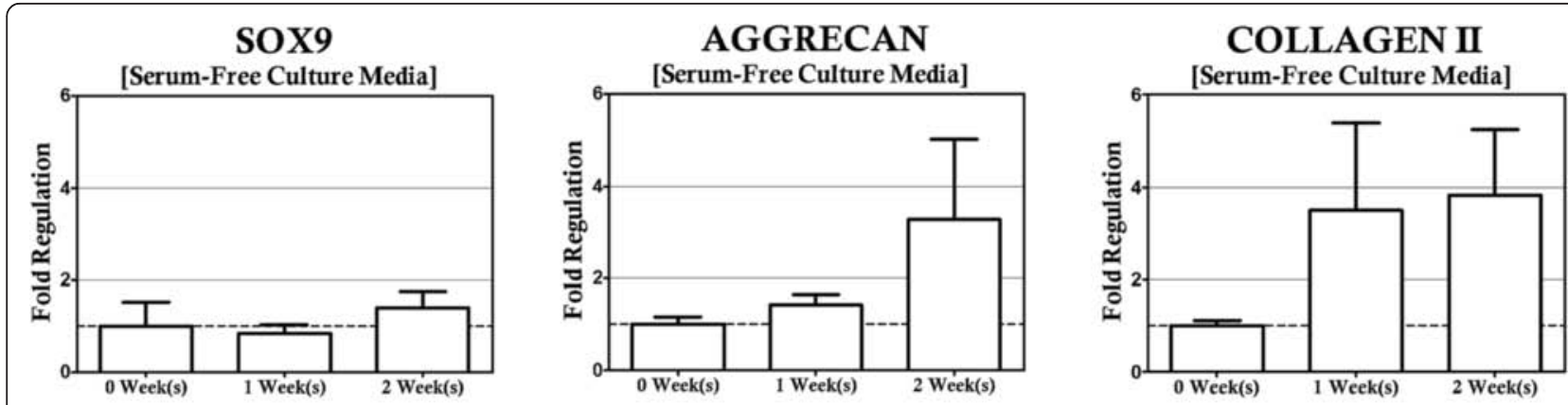

COLLAGEN X

[Serum-Free Culture Media]

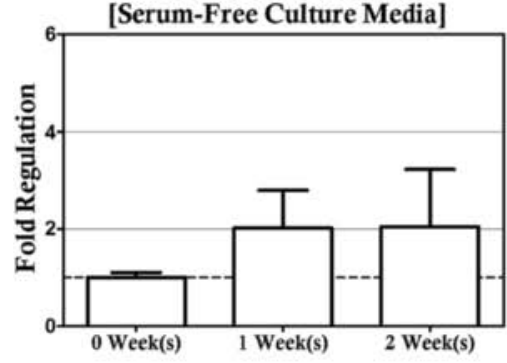

RUNX2

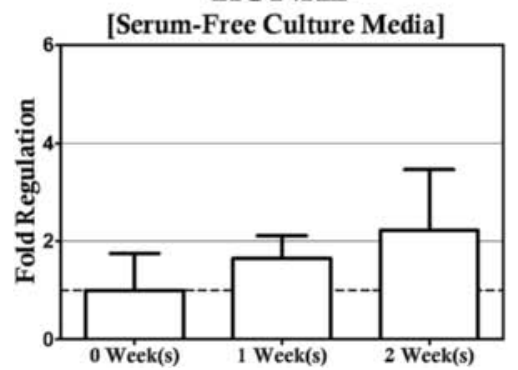

COLLAGEN I

[Serum-Free Culture Media]

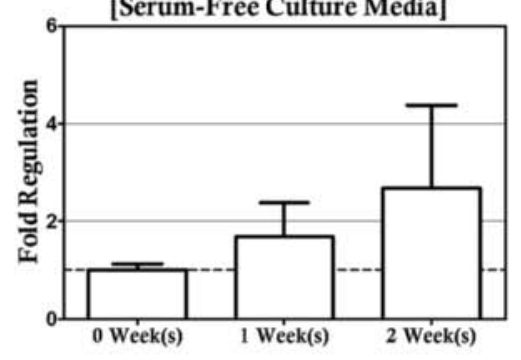

ACTB

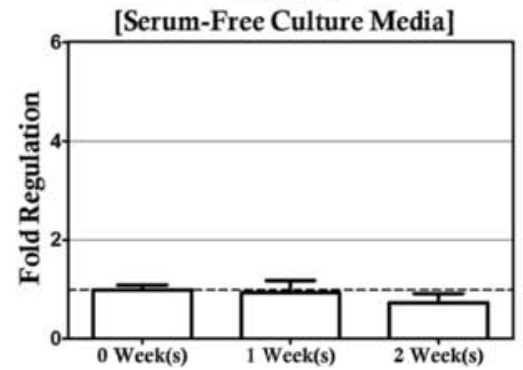

OSTEOCALCIN

[Serum-Free Culture Media]

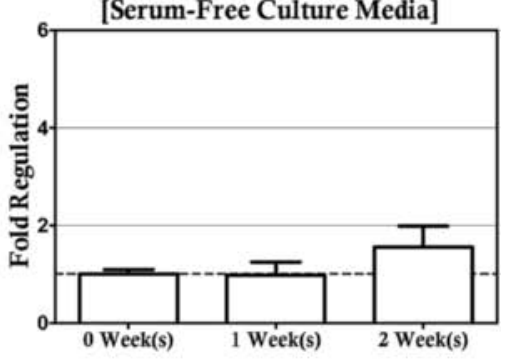

GAPDH

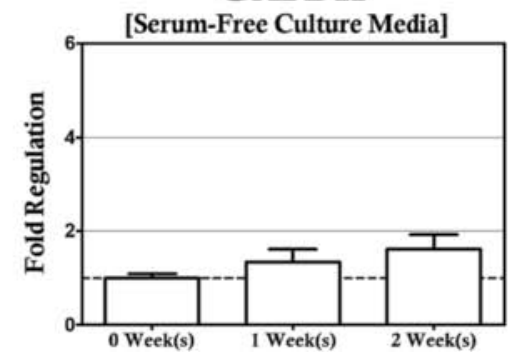

Fig. 2 Gene Expression profiles were determined for unsupplemented, static cultures via RT-qPCR. No statistically significant regulation of the genes in the panel was observed 
to cell contact, a factor known to play a role in chondrogenesis [27], and the deviation of the observations produced between these different systems may exist due to the relative differences in cell density between the two culture types. It is also noteworthy that the seeding density of the constructs was not varied in this study. It is possible seeding density may also play a role in this observation, as prior literature indicates seeding density can have an impact on ECM deposition in MSC-based tissue constructs [28, 29]. While regulation of the chondrogenic markers herein was not found to be significant these factors may play a role in the weak upward trend of COL2A1 with time in culture. Nevertheless, this effect was small and our observations confirmed the utility of this culture condition as a suitable control for our subsequent hydrodynamic culture studies aiming to determine the effect of exogenous cytokine supplementation on the mRNA expression profiles of this MSC population.
Effect of hydrodynamic loading on unsupplemented cultures

With a suitable control group established, the first step in addressing the potential of hydrodynamic loading as a differentiation tool was to culture MSC based tissue constructs under laminar flow profiles with nominal shear stress magnitudes of 1 and $10 \mathrm{dyn} / \mathrm{cm}^{2}$ and to compare the expression of a panel of genes spanning the phenotypic diversity of cells along the endochondral ossification pathway to the previously discussed static controls. When hydrodynamic culture was introduced as a variable to the three-dimensional, serum-free cultures (Fig. 3), no significant regulation of the chondrogenic gene panel was observed, significant upregulation of the osteogenic transcription factor (RUNX2), and two of the three collagens investigated (COL1A1 and COLXA1) occurred under high shear conditions. RUNX2 and COLXA1 were both upregulated early in cultivation (1-week) and remained elevated relative to both the time matched static

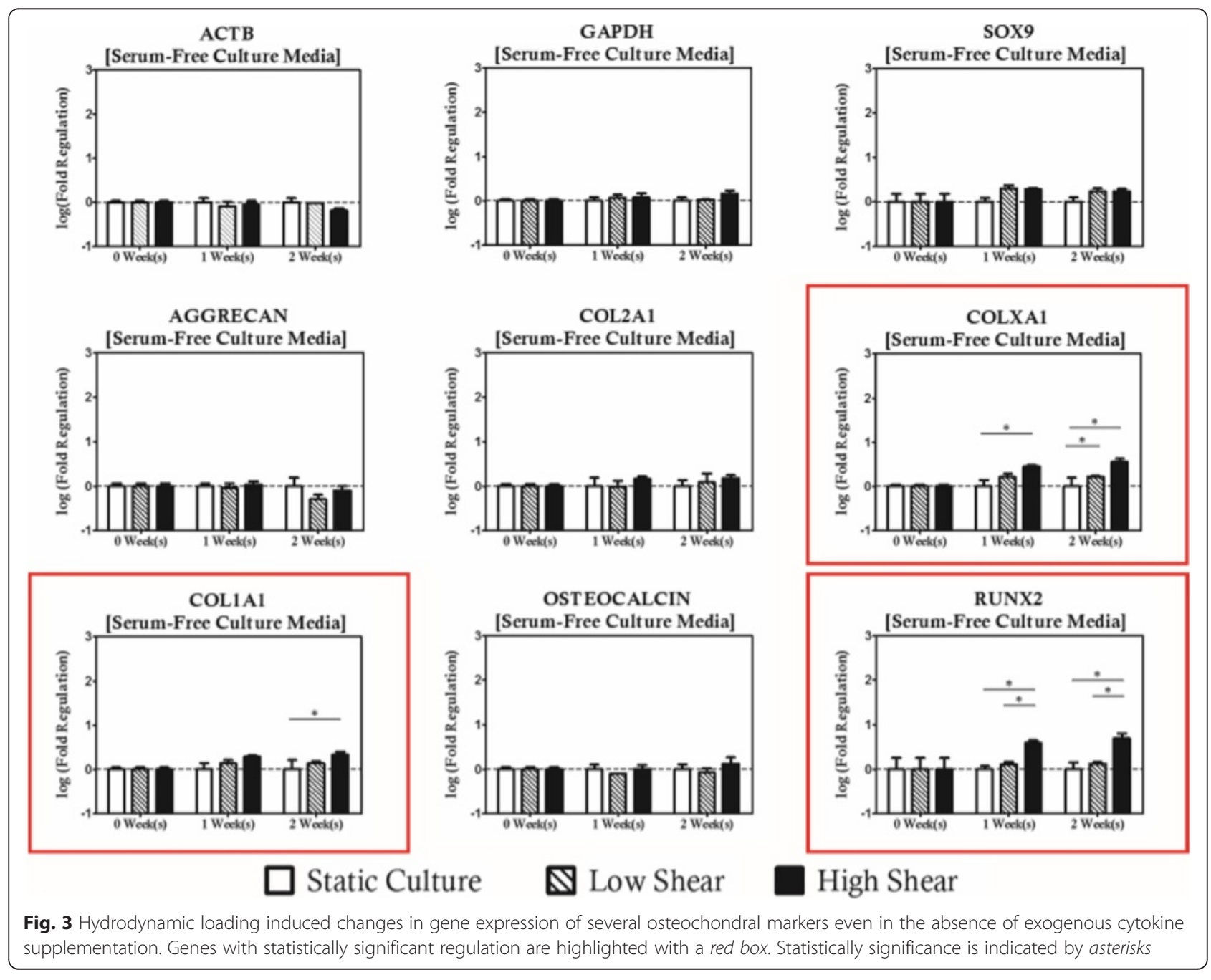


controls and the low shear treatment. At the 2-week time point, upregulation of COL1A1 was considered significant relative to the static cultures. Interestingly, no significant difference in gene expression was observed with lower magnitude hydrodynamic loading, indicating that magnitude of shear in the absence of exogenous cytokine supplementation is not inconsequential. While these changes are considered statistically significant, the nominal change in expression of these genes was of less than one order of magnitude from the expression profile measured in the cell source population. When compared to the magnitude of impact of cytokine supplementation on gene expression when controlled for culture duration $(>2$ orders of magnitude difference), this effect is not likely to be useful as a tool for directed differentiation. At the same time, however, this finding suggests that great care should be taken to minimize the hydrodynamic loading applied to MSC expansion cultures in upstream bioprocessing procedures to prevent non-specific induction of undesirable phenotypes.

\section{Effect of cytokine supplementation on differentiation} markers

While hydrodynamic loading in isolation of exogenous supplementation is not sufficiently potent to control differentiation in a selective manner, the results of our initial studies in unsupplemented, serum-free cultures suggested that hydrodynamic loading may be useful as when presented in concert with morphogens with a known inductive capacity. To investigate this possibility, we analyzed the expression profiles of statically cultured constructs which received either TGF- $\beta 3$ or BMP- 2 supplementation at a concentration of $1,10 \mathrm{ng} / \mathrm{mL}$, or $100 \mathrm{ng} / \mathrm{mL}$ for the purpose of inducing a chondrogenic or osteogenic phenotype, respectively. The resident MSCs tend towards expression of chondrogenic markers as function of time in culture and concentration of exogenous cytokine supplementation for both BMP- 2 and TGF- $\beta 3$ supplementation.

For TGF- $\beta 3$ supplemented cultures, the expression of all three chondrogenic markers increased significantly relative to the unsupplemented control group for culture

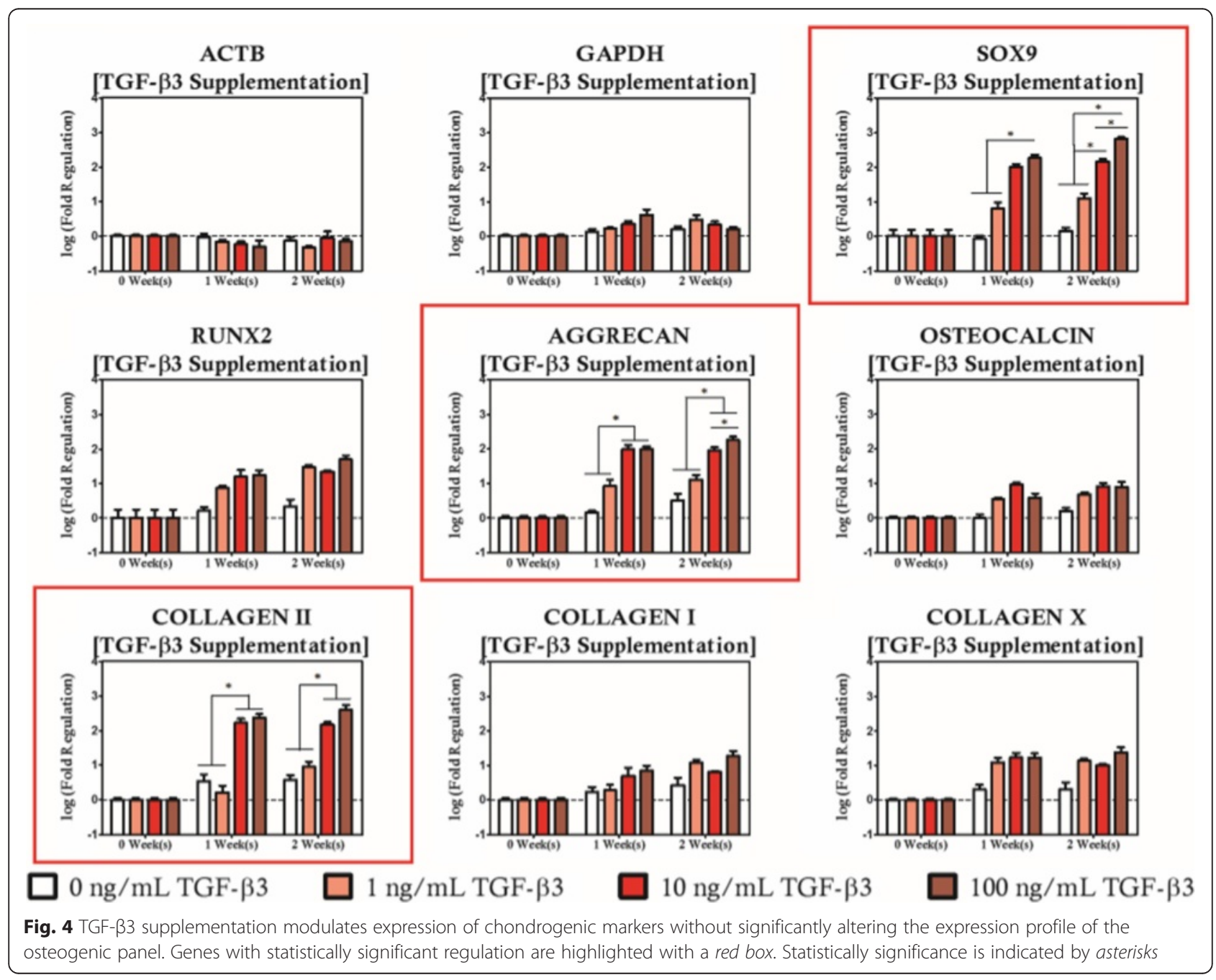


durations of at least 2 weeks provided the culture medium was supplemented with TGF- $\beta 3$ at a concentration of at least $10 \mathrm{ng} / \mathrm{mL}$ while differences in expression of the chondrogenic markers for cultures supplemented at concentrations lower than $10 \mathrm{ng} / \mathrm{mL}$ were not considered significant (Fig. 4). After two weeks of culture, SOX9 was expressed in a concentration dependent manner as the greatest change in expression relative to the source cell population occurred in the $100 \mathrm{ng} / \mathrm{mL}$ supplementation group (667 fold) which was significantly higher than the $10 \mathrm{ng} / \mathrm{mL}$ supplementation group (145 fold), which in turn was significantly greater than the $1 \mathrm{ng} / \mathrm{mL}$ supplementation group (12.7 fold). A similar trend in AGGRECAN and COL2A1 expression was observed as increases in AGGRECAN expression relative to the source cell population was highest in the $100 \mathrm{ng} / \mathrm{mL}$ supplementation group (181 fold), which was statistically indeterminate from the $10 \mathrm{ng} / \mathrm{mL}$ supplementation protocol, but significantly higher than $1 \mathrm{ng} / \mathrm{mL}$ or lower concentration supplementation protocols. Likewise, COL2A1 expression reached a maximum among the static cultures when TGF- $\beta 3$ supplementation was provided at a concentration of $100 \mathrm{ng} / \mathrm{mL}$ (403 fold) for a period of 2 weeks. Considering the expression of undesirable hypertrophic and osteogenic genes, we found comparable mRNA levels among all TGF- $\beta 3$ supplementation protocols. Additionally, the expression level of the hypertrophic and osteogenic markers are statistically indeterminate from the unsupplemented controls.

For BMP-2 supplemented cultures, upregulation of genes from both the chondrogenic and osteogenic panels at high cytokine concentrations was evident (Fig. 5). When the culture medium was supplemented with BMP-2 in concentrations in excess of $10 \mathrm{ng} / \mathrm{mL}$, the entire chondrogenic gene panel (SOX9, AGGRECAN, and COL2A1) was upregulated relative to duration matched cultures receiving BMP-2 supplementation at a concentration of $1 \mathrm{ng} /$ $\mathrm{mL}$ or less. Hypertrophic marker COLXA1 also showed increases with respect to duration matched unsupplemented controls as BMP-2 concentration was increased. Regarding

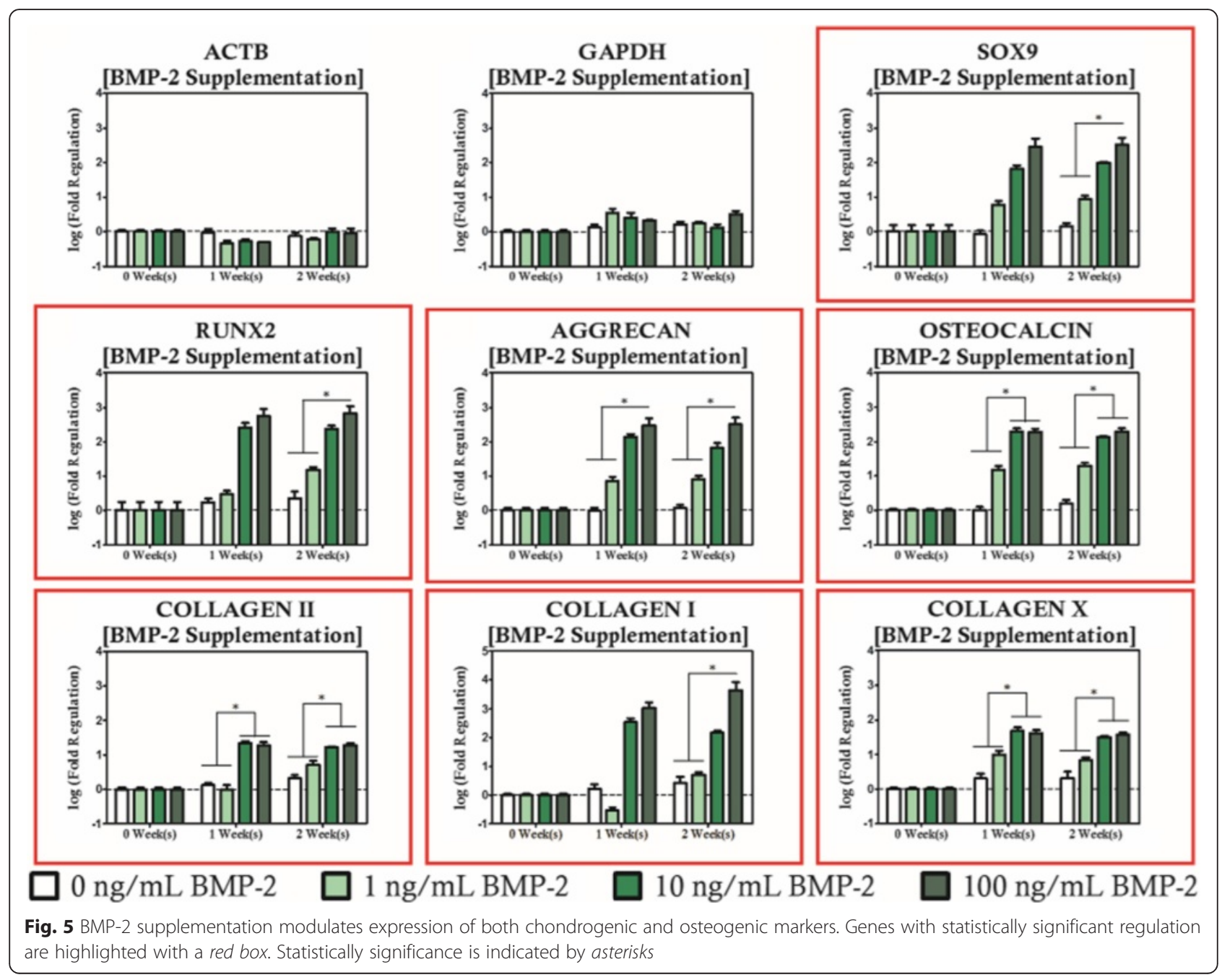


the osteogenic gene panel, OSTEOCALCIN was upregulated in cultures supplemented at $10 \mathrm{ng} / \mathrm{mL}$ or greater relative to duration matched cultures receiving $1 \mathrm{ng} / \mathrm{mL}$ or less for each culture period studied. RUNX2 and COL1A1 were also upregulated relative to the low supplementation groups ( 0 and $1 \mathrm{ng} / \mathrm{mL}$ ), but only when BMP-2 supplementation was provided at a concentration of at least $100 \mathrm{ng} / \mathrm{mL}$ for a period of 2 weeks.

\section{Effect of hydrodynamic loading on cytokine supplemented cultures}

Both BMP- 2 and TGF- $\beta 3$ produced strong differentiation of the MSC population utilizing the static culture platform, and provided a baseline for normalization of the hydrodynamically loaded cultures to control for the independent effect of the cytokines so that we might investigate whether stimulation via hydrodynamic loading can induce a synergistic effect on the gene expression profile of the differentiating cell population.
BMP-2 supplemented cultures exhibited a strong shear coupling with respect to expression of $S O X 9, R U N X 2$, and all of the collagens studied, and was strongly biased towards high magnitude loading protocols (Figs. 6, 7 and 8). It is apparent that RUNX2 was strongly upregulated for all BMP-2 supplementation protocols with concurrent high magnitude hydrodynamic loading as evidenced by significant increases relative to time-matched static controls at each time point investigated as well as significantly high expression relative to the low magnitude loading when BMP-2 concentration was at least $10 \mathrm{ng} / \mathrm{mL}$. In addition to changes in expression of $R U N X 2$, it was also observed that COL1A1 was upregulated for the high shear condition groups. For the $1 \mathrm{ng} / \mathrm{mL}$ BMP-2 group, COL1A1 expression was significantly higher in the high shear group compared to the static controls at two weeks of culture. When the concentration was raised to $10 \mathrm{ng} / \mathrm{mL}$ (Fig. 7) it was observed that the behavior was sustained in addition to being significantly higher than the low magnitude loading group. When BMP-2 supplementation was provided

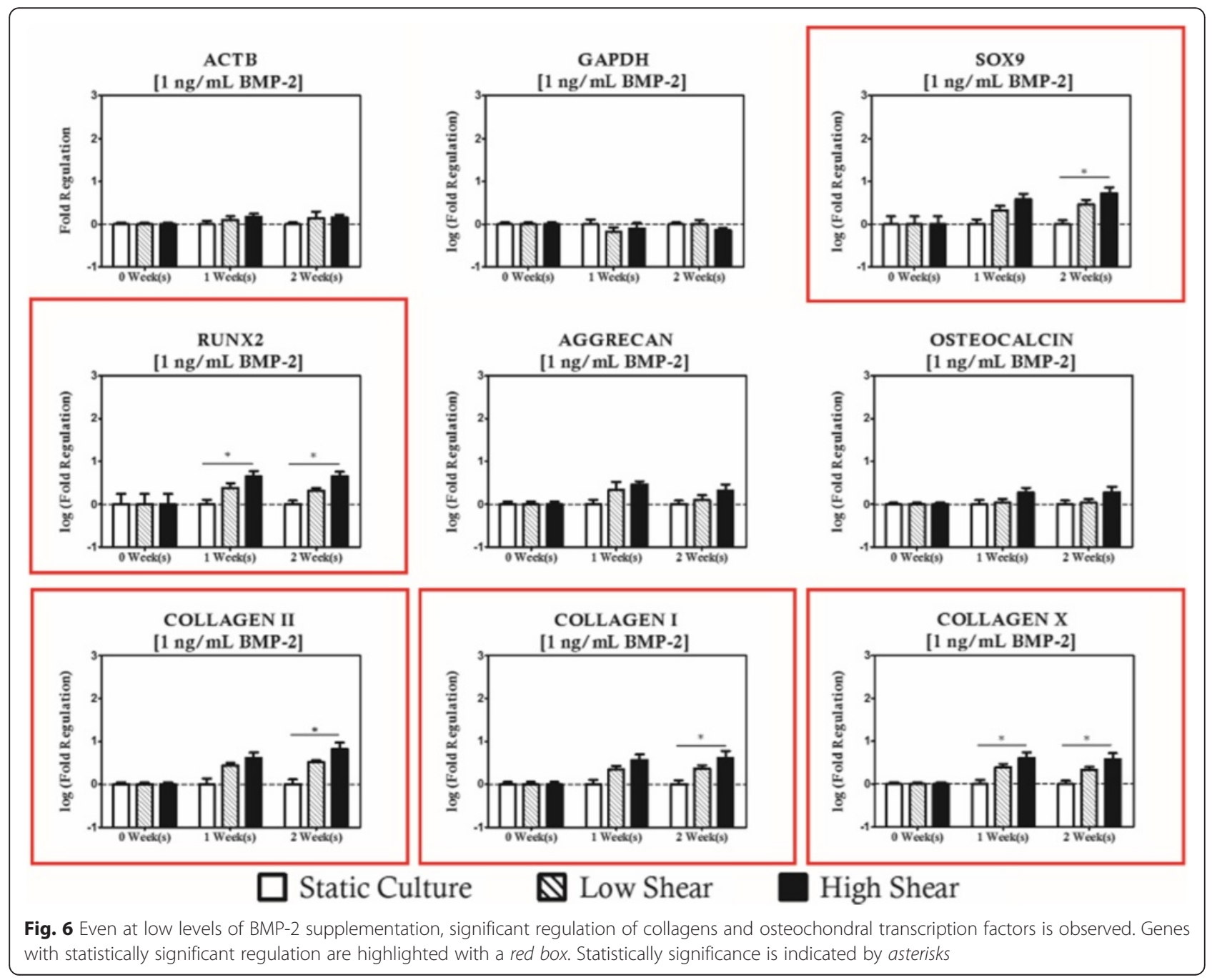




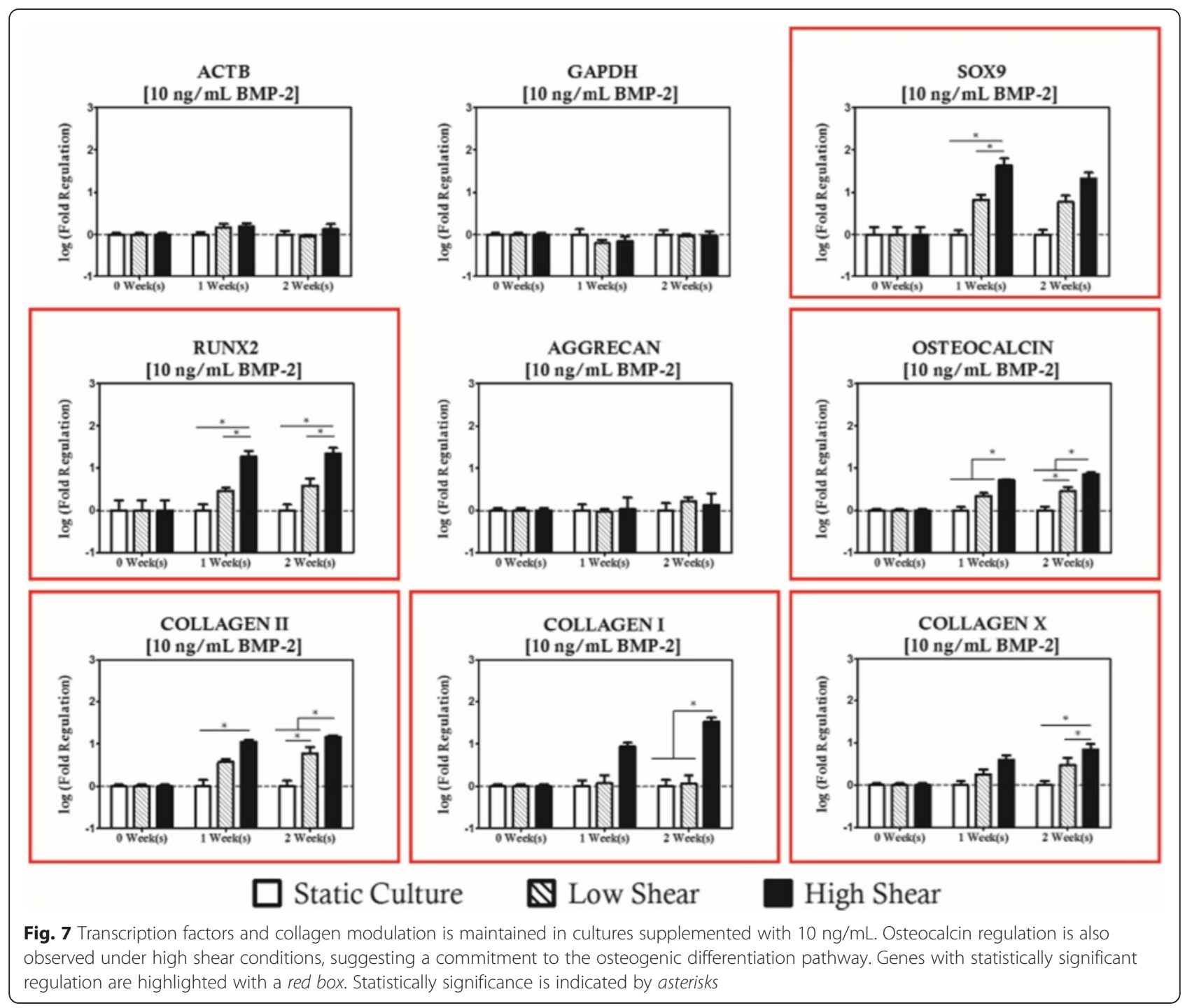

at a concentration of $10 \mathrm{ng} / \mathrm{mL}$ or lower, there was no significant difference in expression between the static and low magnitude hydrodynamic groups for either RUNX2 or COL1A1. When BMP-2 supplementation was increased to $100 \mathrm{ng} / \mathrm{mL}$ (Fig. 8), however, it was observed that COL1A1 was significantly upregulated in the low magnitude loading group relative to the static control after 2 weeks of culture. Additionally, hydrodynamic modulation of OSTEOCALCIN expression was observed for the first time in these studies in the high magnitude loading group relative to the static control after 2 weeks of culture in cultures receiving at least $10 \mathrm{ng} / \mathrm{mL}$ of BMP-2.

Regarding the chondrogenic markers, SOX9 was upregulated in high magnitude loading culture relative to the static control for all BMP-2 supplementation groups, but interestingly this effect was only considered significant at the 1-week time point. COL2A1 expression was observed to increase in high magnitude hydrodynamic cultures as well, as evidenced by significant increases relative to static controls at the 2-week time point for cultures receiving $1 \mathrm{ng} / \mathrm{mL}$ of BMP-2 and at both time points for culture receiving at least $10 \mathrm{ng} / \mathrm{mL}$ of BMP-2. This effect also appears to be sensitive the magnitude of hydrodynamic loading as significant differences were observed between the static cultures and low magnitude cultures as well as between the low and high magnitude cultures. Differences in AGGRECAN expression were only considered significant under high shear and high supplementation. It is also worth noting that expression of hypertrophic marker COLXA1 was significantly increased in the high magnitude loading group after 2 weeks of culture for all BMP-2 supplementation protocols relative to the static control for the low concentrations $(1 \mathrm{ng} / \mathrm{mL})$ and to both low magnitude and static cultures at elevated concentrations of BMP-2 (10 and $100 \mathrm{ng} / \mathrm{mL}$ ). 


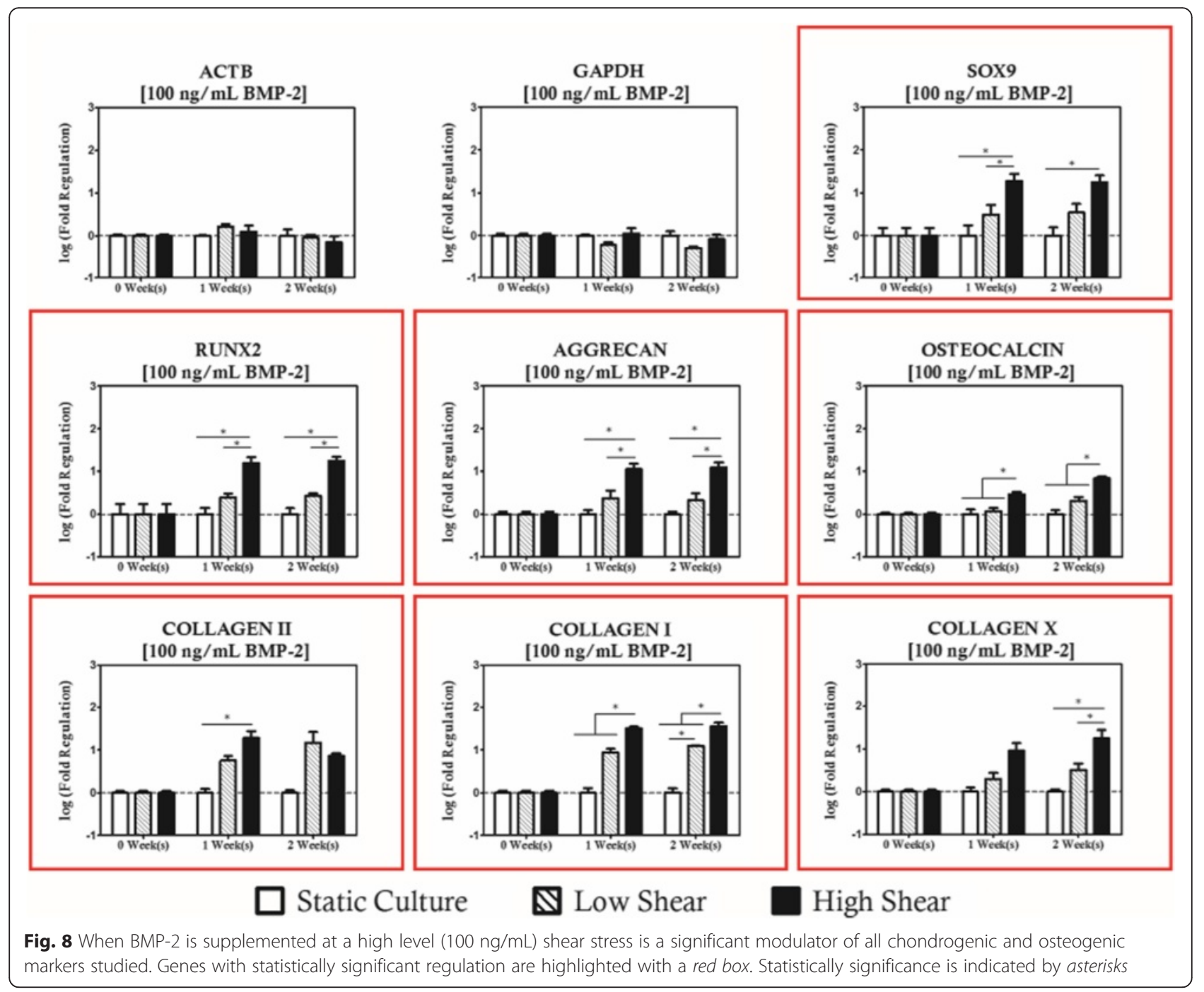

These results are not very surprising in light of the results from unsupplemented, hydrodynamically loaded construct group as two osteoinductive agents, hydrodynamic loading and BMP-2 supplementation, are at work simultaneously in these protocols. While the slight chondrogenic character of these cultures is not desirable, it is worth noting that modulation of chondrogenic markers (SOX9, COL2A1) at high shear was of less than an order of magnitude and the order of the baseline control expression of these genes was considerably lower than their chondrogenic counterparts. COLXA1 expression increased by an order of magnitude over culture period and supplementation matched static controls for both low and high shear conditions at two weeks when cultures were supplemented with $100 \mathrm{ng} / \mathrm{mL}$ of BMP-2. While the inductive impact of hydrodynamic loading is not as great in magnitude as that of BMP-2 supplementation at high levels (one order of magnitude change vs three orders of magnitude), it none the less is an important modulator of osteogenic induction as no significant difference was observed between static cultures supplemented at $100 \mathrm{ng} / \mathrm{mL}$ and cultures supplemented at $10 \mathrm{ng} / \mathrm{mL}$ that were also subjected to high magnitude hydrodynamic loading in terms of total gene expression relative to the initial MSC population.

When hydrodynamic stimulation was introduced in concert with TGF- $\beta 3$ supplementation, it was observed that $C O L 2 A 1$ was upregulated relative to duration and supplementation group matched controls when the hydrodynamic loading condition was high $\left(10 \mathrm{dyn} / \mathrm{cm}^{2}\right)$ and TGF- $\beta 3$ concentrations were low indicating a mild synergistic effect on the chondrogenic induction of the resident cell population (Fig. 9). When the supplementation protocol was increased to $10 \mathrm{ng} / \mathrm{mL}$, high shear cultures resulted in upregulation of both $S O X 9$ and COL2A1. No regulation of hypertrophic or osteogenic markers was observed at this supplementation level, and interestingly there was no effect on chondrogenic markers in low 


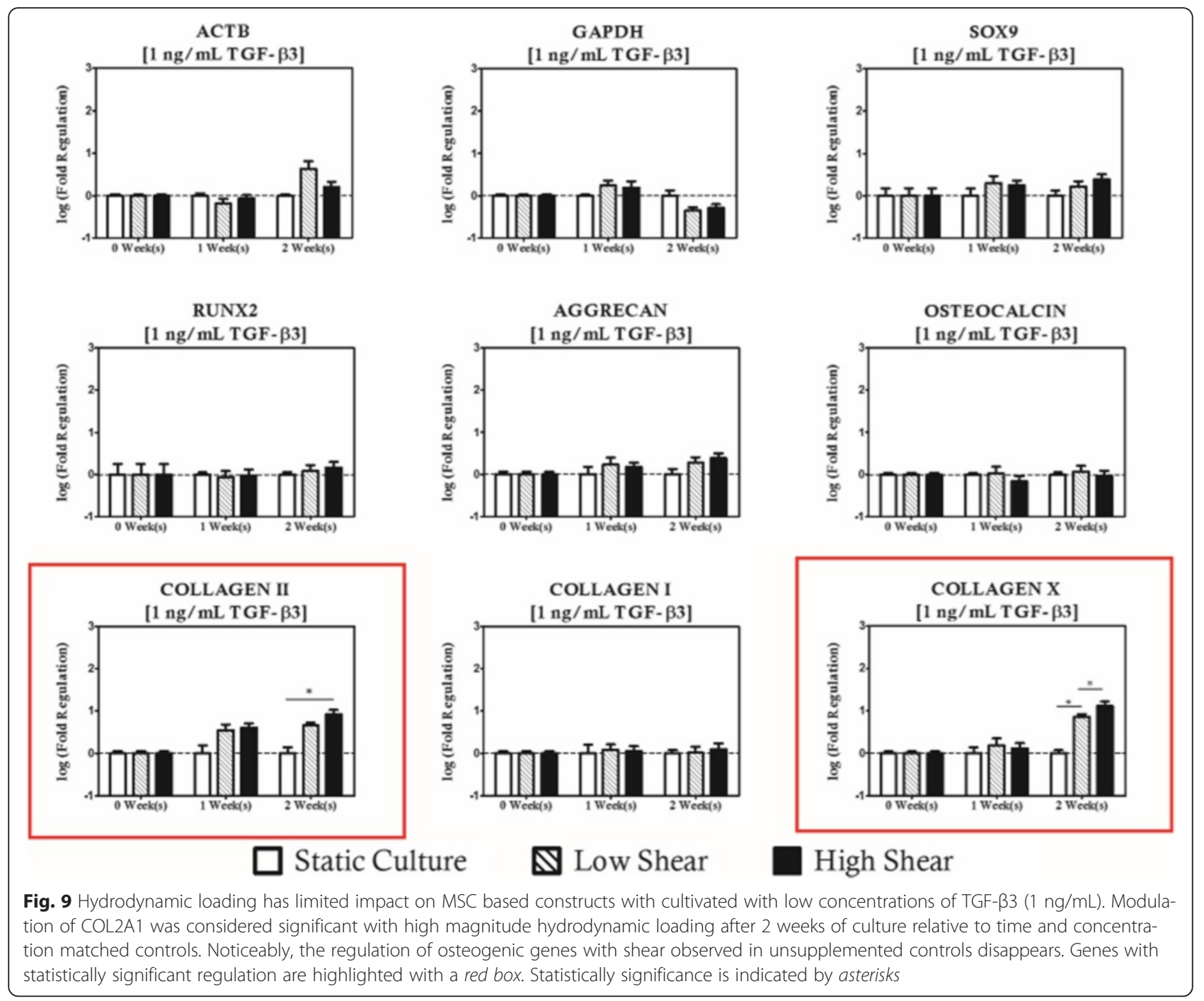

magnitude hydrodynamic cultures (Fig. 10). Upon increasing the TGF- $\beta 3$ protocol to $100 \mathrm{ng} / \mathrm{mL}$, shear magnitude dependent modulation of all three chondrogenic genes studied was observed. The chondrogenic panel was upregulated under high magnitude shear conditions relative to static controls after 1 week of culture and remained significantly high for subsequent culture durations (Fig. 11). There was no statistical difference between low and high shear conditions for COL2A1 and AGGRECAN expression, but there was a shear magnitude dependency observed for SOX9.

Interestingly, changes in expression of the osteogenic gene panel were not considered significant for any of the hydrodynamic regimes studied. Expression of COLXA1, however, was upregulated relative to concentration matched static controls when conditions were such that high shear magnitudes $\left(10 \mathrm{dyn} / \mathrm{cm}^{2}\right)$ were paired with low $(1 \mathrm{ng} / \mathrm{mL})$ concentrations of TGF- $\beta 3$ for a period of at least 2 weeks. No significant changes in COLXA1 were observed with moderate or high TGF- $\beta 3$ supplementation. These observations hint at two potentially useful characteristics of this approach. First, chondrogenic differentiation is clearly positively influenced by the presence of hydrodynamic loading when presented in concert with at least $10 \mathrm{ng} / \mathrm{mL}$ of TGF- $\beta 3$, and that TGF- $\beta 3$ signaling appears to have an inhibitory effect the on the osteoinductive role of high magnitude hydrodynamic loading observed with the other supplementation protocols studied herein.

\section{Histology \& immunofluorescence}

Histological staining and immunofluorescence of 2-week culture samples qualitatively supports the gene expression profiles observed through PCR (Figs. 12, 13 and 14). Toluidine Blue staining indicates increasing expression of sulfated glycosaminoglycans with increases in both BMP-2 and TGF- 33 supplementation, while Alizarin Red staining shows greater staining with increased 


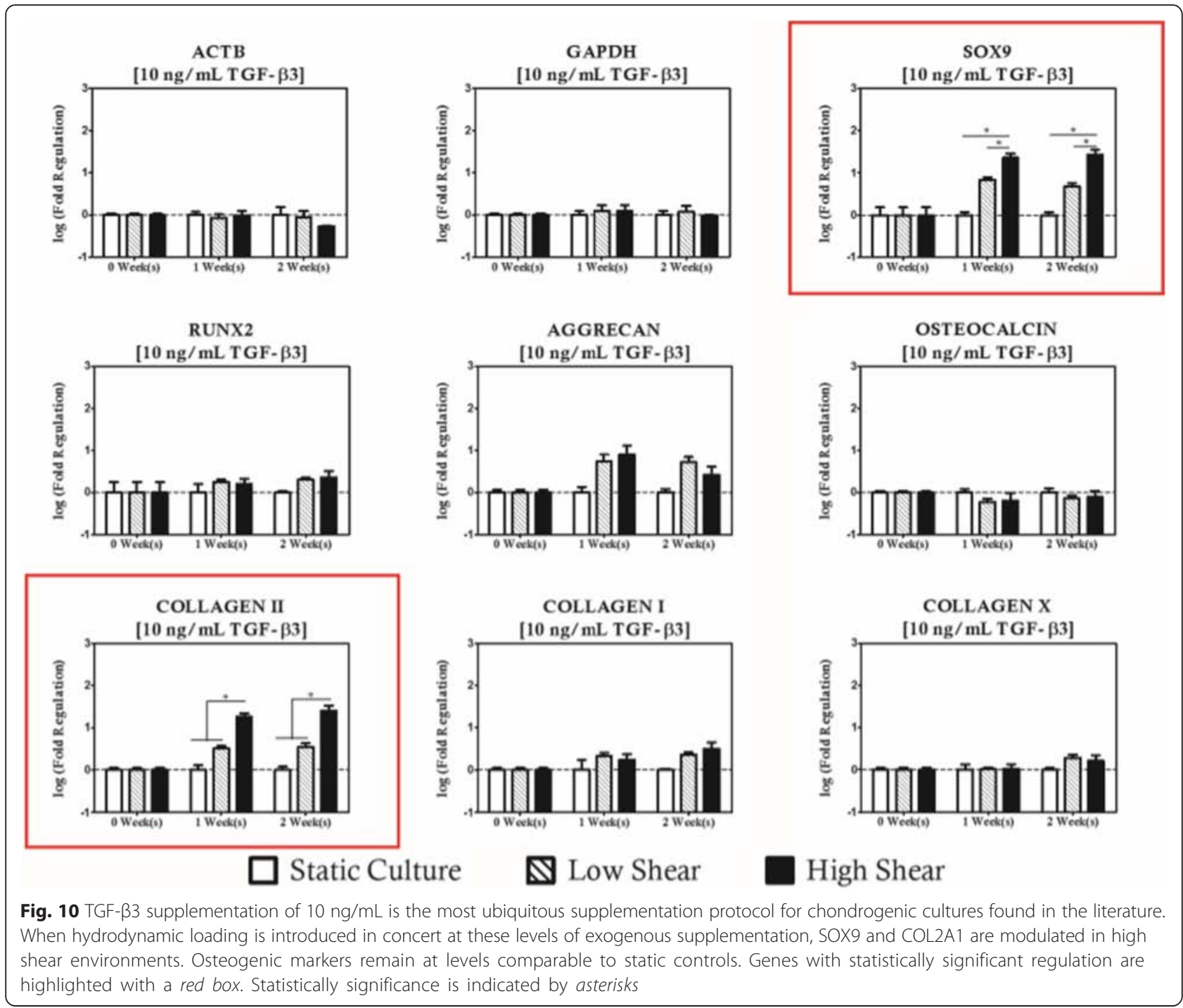

BMP-2 supplementation. Alizarin Red staining was relatively uniform for TGF- $\beta 3$ supplemented cultures for all hydrodynamic and supplementation protocols tested. Immunofluorescence indicates increasing Collagen type I and Collagen type II expression in the BMP-2 and TGF$\beta 3$ supplemented cultures of increasing concentration, respectively. Trends in collagen expression between shear conditions are less clear, but there appears to be more total collagen in BMP-2 supplemented cultures on the whole, and total collagen expression appears to increase with hydrodynamic loading.

\section{Discussion}

As the predominate source of cells for tissue engineered constructs has shifted from terminally differentiated primary cells towards progenitor cells of various differentiation potentials, the ability to spatiotemporally exert epigenetic control over the differentiation of stem cells within a tissue engineered construct has become desirable as a means to better reproduce native tissue complexity and reduce cultivation costs associated with traditional differentiation protocols. Subsequently, we decided to focus herein on the impact of the hydrodynamic environment on MSC differentiation due to its essential role in nutrient exchange during in vitro cultivation. The purpose of this study was to investigate how modulation of hydrodynamic loading affects the stability of the MSC phenotype during serum-free tissue culture and how this approach might enhance differentiation efficiency in the presence of morphogens known to be either osteoinductive or chondrogenic in nature. Our primary findings (Additional file 1: Table S3) were that hydrodynamic loading, in the absence of exogenous supplementation, promotes expression of hypertrophic and osteogenic genes. Although not investigated in this study, we suspect this observation is due to integrin 


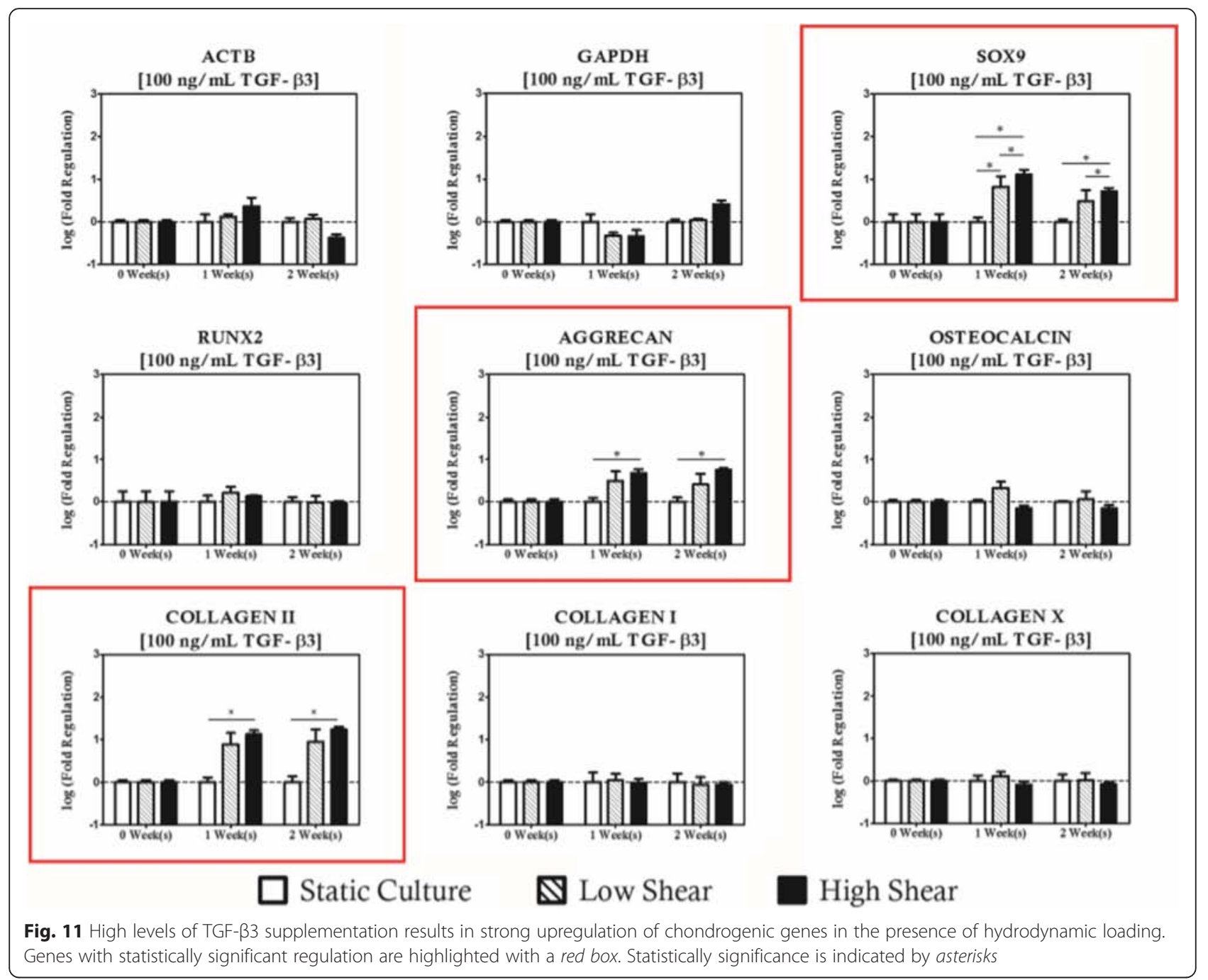

signaling activated by deformation of the MSC pericellular matrix in response to the hydrodynamic loads as indicated by other studies in the literature [30,31]. The influence of hydrodynamic loading on osteogenic markers was sustained for low levels of exogenous supplementation irrespective of the cytokine provided. Lineage specific upregulation towards chondrogenic and osteogenic phenotypes was observed under high magnitude shear conditions when hydrodynamic loading was presented in concert with high levels of TGF- $\beta 3$ and BMP-2 supplementation respectively. Generally, the observed impact of hydrodynamic loading on the desired phenotypes was greater in longer term cultures, and in cultures receiving higher concentrations of exogenous cytokines.

These findings are in agreement with prior mechanobiological studies in other osteochondral lineage cell sources. In studies based on osteoblastic cell lines, multiple studies have shown that hydrodynamic loading is osteopromotive [32-36], and often results in increases in type I collagen production and matrix mineralization.
Hydrodynamic studies on MSCs from various donor species have also been previously shown to be osteoinductive [37-39]. Additionally, multiple studies on primary chondrocytes have shown that in addition to increases in type II collagen [40, 41]. Exposure to high shear environments can result in development of a fibrous layer rich in non-hyaline type I collagen at shear exposed surfaces [42], particularly when cultured with serum supplemented medium [43] versus serum free preparations. If we compare the extent of the impact of hydrodynamic loading on unsupplemented cultures in our study to that of other environmental induction schemes for MSCs, we find that the effect on gene expression is on the same order of magnitude as manipulations of scaffolding stiffness for osteoinduction [44] and both hydrostatic pressure [45] and dynamic unconfined compressive loading $[46,47]$ for chondrogenic induction. Unlike these prior studies, however, we found the impact of exogenous supplementation on gene expression to be considerably greater than the environmental stimulus 


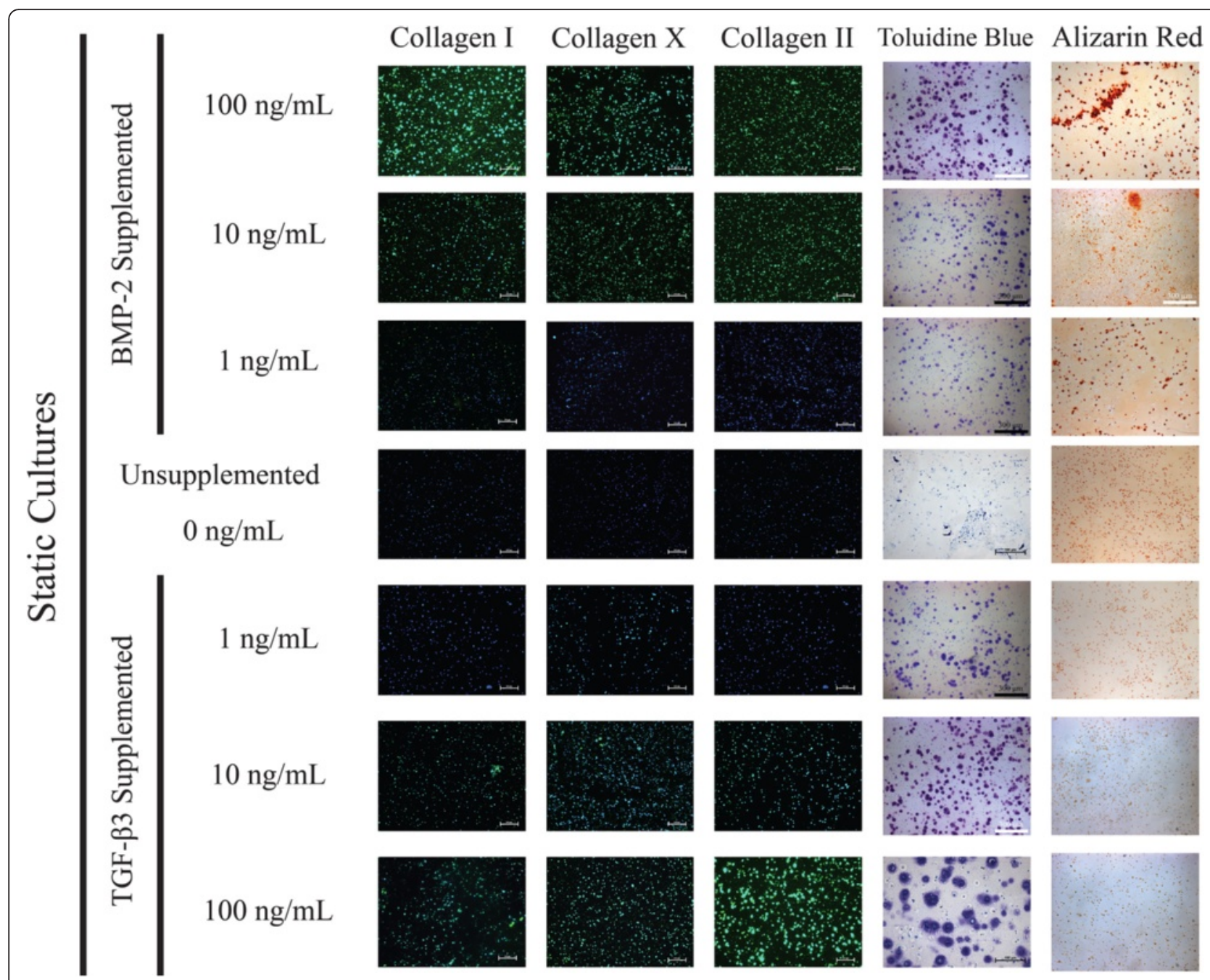

Fig. 12 Histological and Immunofluorescence analyses of static cultures suggest increasing osteogenic character with BMP-2 supplementation and increasing chondrogenic character with TGF- $\beta 3$ supplementation

applied. Our results converge again, however, when the mechanical stimuli were presented concurrently with TGF- $\beta 3$ supplementation $[45,46]$. As in our study utilizing hydrodynamic loading, dynamic compression and intermittent hydrostatic loading both resulted in additional increases in chondrogenic gene expression when presented in cultures supplemented with at least $10 \mathrm{ng} /$ $\mathrm{mL}$. The order of magnitude of the change, however, is considerably greater in our hydrodynamic study $(>100$ fold change) than either of the prior studies utilizing compressive $(<10$ fold change) and hydrostatic $(<10$ fold change) loading.

Conversely, other studies have shown compressive loading to have a negative impact on glycosaminoglycan accumulation within the construct at the protein level [48]. It is unclear, however, if this effect is due to decreased synthesis or loss of glycosaminoglycans to the culture medium. Interestingly, the same study [48], also showed that dynamic compressive loading resulted in increases in COLXA1 in the absence of TGF- $\beta 3$ supplementation, a result that mirrors our findings of both a hypertrophic influence of unsupplemented hydrodynamic loading and of the chondroprotective character of TGF- $\beta 3$ supplementation. Our findings, herein, seem to indicate a comparable role of hydrodynamic loading to that of other environmental factors, particularly dynamic compression. Considering finite element analyses have shown interstitial fluid flow to be an effect of dynamic loading in biphasic materials such as those referenced herein, it is not surprising that these two loading conditions produce similar responses in MSC based tissue constructs.

Our finding that high magnitude hydrodynamic loading promotes osteogenic gene expression in unsupplemented cultures is instructive and suggests that MSCs cultures intended for chondral therapies not be subjected to high 


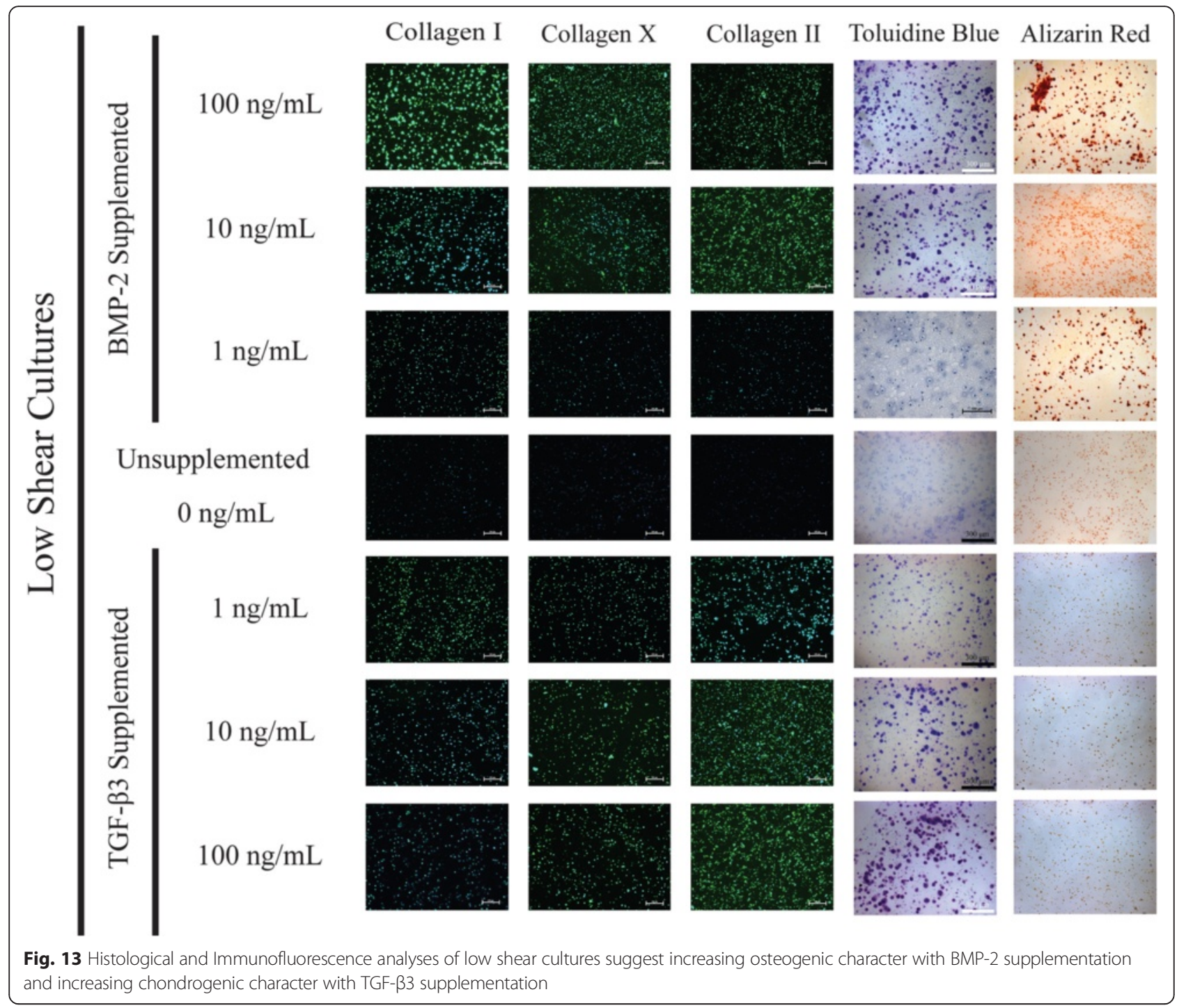

shear hydrodynamic loading conditions during processing and cultivation. While the modified parallel plate bioreactor system utilized better utilized for experimental investigation than a scalable manufacturing process, the bioprocessing principles derived from its use could easily be incorporated into a more scalable suspension bioreactor system based on three dimensional microcarriers. It is our recommendation that the nutrient utilization of chondrogenic cultures in such a system be carefully considered such that fluid loading not be applied in excess of magnitudes needed to meet the convective transport demands of the tissue in order to avoid potential induction of a hypertrophic phenotype. Conversely, our findings also suggest hydrodynamic loading of osteogenic cultures can potentially be a means of either reducing culture dependence on exogenous cytokines or promoting increased matrix deposition provided the magnitude of loading is increased such that impacts cell viability in a negative manner [49].

\section{Conclusions}

The findings of this study bring forth a number of important considerations regarding hydrodynamic culture of MSC based constructs for tissue engineering applications. As evidenced by results from all cytokine supplementation groups, including serum-free expansion medium culture, it is clear that MSCs are tuned to their local mechanical loading environment, and that prolonged exposure to high magnitude fluid shear stresses induces a hypertrophic phenotype amongst the resident MSCs ultimately resulting in expression of osteogenic markers. For the purpose of chondrogenic cultures, therefore, our results suggest minimizing the fluid shear 


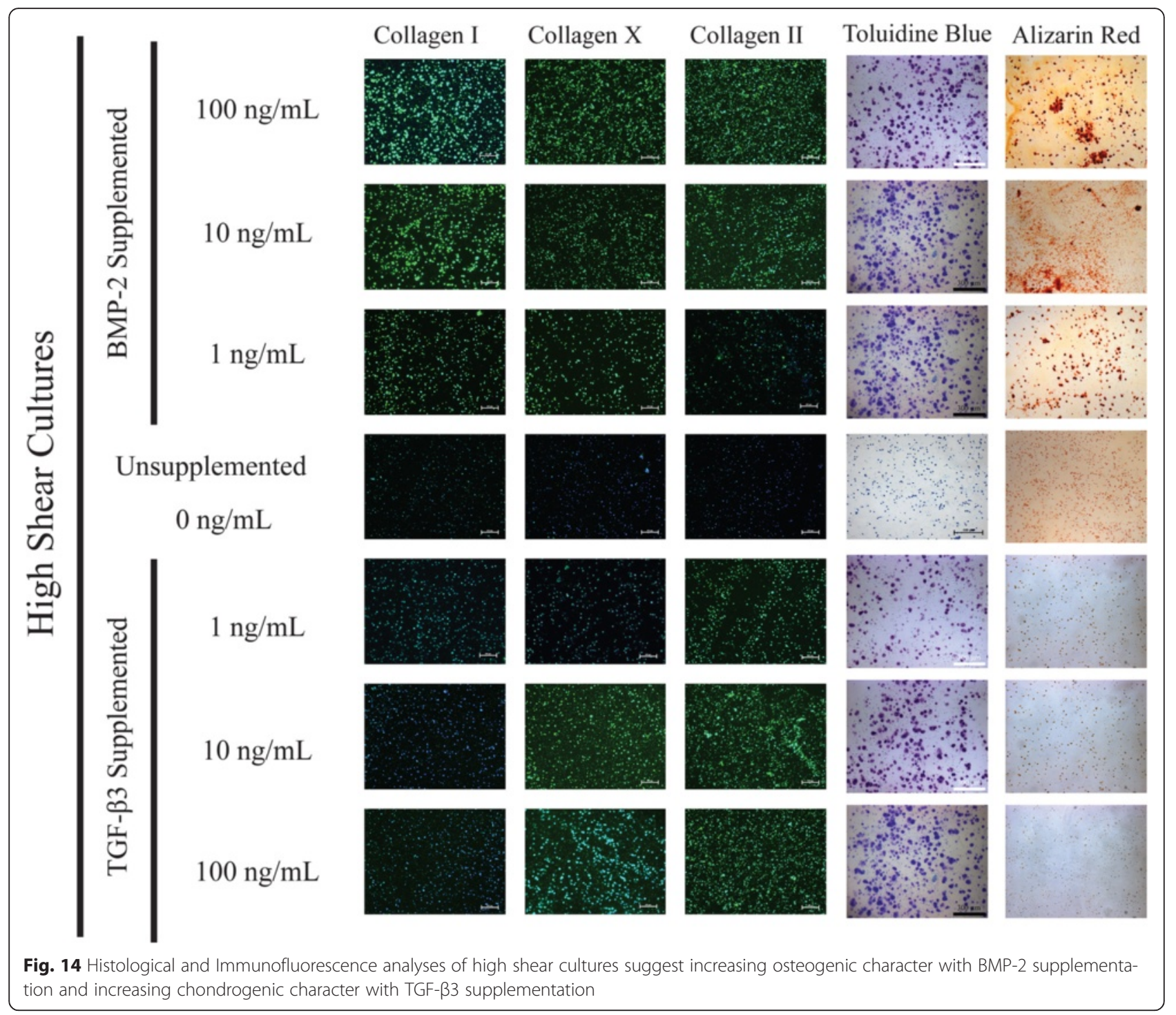

stress imposed on the developing construct without reducing the transport of nutrients to all regions of the tissue construct. Furthermore, this phenomenon presents an interesting paradigm for the production of osteochondral tissue constructs through differential loading of the construct, both chemically and hydrodynamically, by varying the microenvironment appropriately in spatially separated regions of the tissue construct. While the overall goal of the current study of a single medium source with differential loading to induce phenotypic changes in the MSC population was not achieved, there is evidence that loading will play a significant role in bioprocessing protocols of osteochondral constructs moving forward as technologies such as microfluidic hydrogels [50-53] provide the means to differentially apply chemical and environmental cues within an integrated construct of a single cell type to spatially engineer osteochondral tissues for intra-articular injury repair and preclinical models for pharmacological studies against osteoarthritis.

\section{Additional files}

Additional file 1 Table S1. Experimental Condition Matrix. Table S2. RT-qPCR Primers. Table S3. Summary of Transcriptome Analysis after 2-Weeks of Culture. Table S4. Gene Regulation Ratios. (DOCX $21 \mathrm{~kb}$ )

Additional file 2: Supplementary Methods. (DOCX $17 \mathrm{~kb}$ )

Additional file 3: Figure S1. Adherent cells were lifted from culture after one passaging and test for the presence of bovine MSC surface markers consisting of CD271, CD166, and CD44. Additionally, cells were tested for the absence of hematopoietic surface marker CD45. (TIF 2104 kb)

Additional file 4: Figure S2. Following confirmation of MSC surface markers via flow cytometry, MSCs from the bone marrow of three calves were pooled, plated, cultured and assessed for tri-lineage differentiation potential. From left to right MSCs culture in inductive media (top) and growth medium (bottom row) were stained with Oil Red O, Toluidine Blue, and Alizarin Red to confirm evidence of adipogenesis, chondrogenesis, and osteogenesis respectively. (TIF $26421 \mathrm{~kb}$ ) 


\section{Competing interests}

The authors declare that they have no competing interests.

\section{Authors' contributions}

SMG and GAB conception and design of research; SMG performed experiments and analyzed data; SMG and GAB interpreted results of experiments; SMG prepared figures and drafted manuscript; SMG and GAB edited and revised manuscript; SMG and GAB approved final version of manuscript.

\section{Acknowledgements}

No acknowledgements to report.

\section{Author details}

'Interdisciplinary Bioengineering Graduate Program, Georgia Institute of Technology, Atlanta, GA, 30332, USA. ${ }^{2}$ G.W. Woodruff School of Mechanical Engineering, Georgia Institute of Technology, Atlanta, GA, 30332, USA. ${ }^{3}$ Department of Biomedical Engineering, City College of New York, 160 Convent Avenue, New York, NY, 10031, USA.

\section{Received: 13 May 2015 Accepted: 18 January 2016}

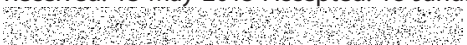

\section{References}

1. Mauck RL, Yuan X, Tuan RS. Chondrogenic differentiation and functional maturation of bovine mesenchymal stem cells in long-term agarose culture. Osteoarthr Cartil. 2006:14(2):179-89.

2. Pittenger MF, Mackay AM, Beck SC, Jaiswal RK, Douglas R, Mosca JD, et al. Multilineage potential of adult human mesenchymal stem cells. Science (New York, NY). 1999;284(5411):143-7.

3. Caplan Al. Review: mesenchymal stem cells: cell-based reconstructive therapy in orthopedics. Tissue Eng. 2005;11(7-8):1198-211.

4. Bruder SP, Jaiswal N, Haynesworth SE. Growth kinetics, self-renewal, and the osteogenic potential of purified human mesenchymal stem cells during extensive subcultivation and following cryopreservation. J Cell Biochem. 1997:64(2):278-94.

5. Cheng SL, Yang JW, Rifas L, Zhang SF, Avioli LV. Differentiation of human bone marrow osteogenic stromal cells in vitro: induction of the osteoblast phenotype by dexamethasone. Endocrinology. 1994;134(1):277-86.

6. Indrawattana N, Chen G, Tadokoro M, Shann LH, Ohgushi H, Tateishi T, et al. Growth factor combination for chondrogenic induction from human mesenchymal stem cell. Biochem Biophys Res Commun. 2004;320(3):914-9.

7. Mackay AM, Beck SC, Murphy JM, Barry FP, Chichester CO, Pittenger MF. Chondrogenic differentiation of cultured human mesenchymal stem cells from marrow. Tissue Eng. 1998:4(4):415-28.

8. Roelen BAJ, Dijke P. Controlling mesenchymal stem cell differentiation by TGFB family members. J Orthop Sci. 2003:8(5):740-8.

9. Worster AA, Brower-Toland BD, Fortier LA, Bent SJ, Williams J, Nixon AJ. Chondrocytic differentiation of mesenchymal stem cells sequentially exposed to transforming growth factor- $\beta 1$ in monolayer and insulin-like growth factor-I in a three-dimensional matrix. J Orthop Res. 2001;19(4):738-49.

10. Marklein RA, Burdick JA. Controlling stem cell fate with material design. Adv Mater. 2010;22(2):175-89.

11. Maul T, Chew D, Nieponice A, Vorp D. Mechanical stimuli differentially control stem cell behavior: morphology, proliferation, and differentiation. Biomech Model Mechanobiol. 2011;10(6):939-53.

12. Guilak F, Cohen DM, Estes BT, Gimble JM, Liedtke W, Chen CS. Control of stem cell fate by physical interactions with the extracellular matrix. Cell Stem Cell. 2009;5(1):17-26.

13. Porter B, Zauel R, Stockman H, Guldberg R, Fyhrie D. 3-D computational modeling of media flow through scaffolds in a perfusion bioreactor. J Biomech. 2005:38(3):543-9.

14. Saini S, Wick TM. Concentric cylinder bioreactor for production of tissue engineered cartilage: effect of seeding density and hydrodynamic loading on construct development. Biotechnol Prog. 2003;19(2):510-21.

15. Bueno EM, Bilgen B, Barabino GA. Wavy-walled bioreactor supports increased cell proliferation and matrix deposition in engineered cartilage constructs. Tissue Eng. 2005;11(11-12):1699-709.

16. Spaulding GF, Jessup JM, Goodwin TJ. Advances in cellular construction J Cell Biochem. 1993;51(3):249-51.

17. Zoro BJ, Owen S, Drake RA, Hoare M. The impact of process stress on suspended anchorage-dependent mammalian cells as an indicator of likely challenges for regenerative medicines. Biotechnol Bioeng. 2008; 99(2):468-74.

18. Papachroni KK, Karatzas DN, Papavassiliou KA, Basdra EK, Papavassiliou AG. Mechanotransduction in osteoblast regulation and bone disease. Trends Mol Med. 2009;15(5):208-16.

19. Szafranski JD, Grodzinsky AJ, Burger E, Gaschen V, Hung HH, Hunziker EB. Chondrocyte mechanotransduction: effects of compression on deformation of intracellular organelles and relevance to cellular biosynthesis. Osteoarthr Cartil. 2004;12(12):937-46.

20. Jeon JE, Schrobback K, Hutmacher DW, Klein TJ. Dynamic compression improves biosynthesis of human zonal chondrocytes from osteoarthritis patients. Osteoarthr Cartil. 2012;20(8):906-15.

21. Huiskes $R$, Ruimerman $R$, van Lenthe $G H$, Janssen JD. Effects of mechanical forces on maintenance and adaptation of form in trabecular bone. Nature. 2000:405(6787):704-6.

22. Fritton SP, Weinbaum S. Fluid and solute transport in bone: flow-induced mechanotransduction. Annu Rev Fluid Mech. 2009:41:347-74.

23. Mow VC, Holmes MH, Michael Lai W. Fluid transport and mechanical properties of articular cartilage: a review. J Biomech. 1984;17(5):377-94.

24. Vandesompele J, De Preter K, Pattyn F, Poppe B, Van Roy N, De Paepe A, et al. Accurate normalization of real-time quantitative RT-PCR data by geometric averaging of multiple internal control genes. Genome Biol. 2002;3(7):Research0034.

25. Marklein RA, Burdick JA. Spatially controlled hydrogel mechanics to modulate stem cell interactions. Soft Matter. 2010;6(1):136-43.

26. Bosnakovski D, Mizuno M, Kim G, Ishiguro T, Okumura M, Iwanaga $T$, et al. Chondrogenic differentiation of bovine bone marrow mesenchymal stem cells in pellet cultural system. Exp Hematol. 2004;32(5):502-9.

27. Tuli R, Tuli S, Nandi S, Huang X, Manner PA, Hozack WJ, et al. Transforming growth factor- $\beta$-mediated chondrogenesis of human mesenchymal progenitor cells involves $\mathrm{N}$-cadherin and mitogen-activated protein Kinase and Wnt signaling cross-talk. J Biol Chem. 2003;278(42):41227-36.

28. Hui TY, Cheung KMC, Cheung WL, Chan D, Chan BP. In vitro chondrogenic differentiation of human mesenchymal stem cells in collagen microspheres: influence of cell seeding density and collagen concentration. Biomaterials. 2008:29(22):3201-12

29. Huang AH, Stein A, Tuan RS, Mauck RL. Transient exposure to transforming growth factor beta 3 improves the mechanical properties of mesenchymal stem cell-laden cartilage constructs in a density-dependent manner. Tissue Eng A. 2009;15(11):3461-72.

30. Salasznyk RM, Klees RF, Williams WA, Boskey A, Plopper GE. Focal adhesion kinase signaling pathways regulate the osteogenic differentiation of human mesenchymal stem cells. Exp Cell Res. 2007;313(1):22-37.

31. Simmons CA, Matlis S, Thornton AJ, Chen S, Wang C-Y, Mooney DJ. Cyclic strain enhances matrix mineralization by adult human mesenchymal stem cells via the extracellular signal-regulated kinase (ERK1/2) signaling pathway. J Biomech. 2003:36(8):1087-96.

32. Yu X, Botchwey EA, Levine EM, Pollack SR, Laurencin CT. Bioreactor-based bone tissue engineering: the influence of dynamic flow on osteoblast phenotypic expression and matrix mineralization. Proc Natl Acad Sci U S A. 2004:101(31):11203-8.

33. Grayson WL, Bhumiratana S, Cannizzaro C, Chao PH, Lennon DP, Caplan Al, et al. Effects of initial seeding density and fluid perfusion rate on formation of tissue-engineered bone. Tissue Eng A. 2008;14(11):1809-20.

34. Bancroft GN, Sikavitsas VI, van den Dolder J, Sheffield TL, Ambrose CG Jansen JA, et al. Fluid flow increases mineralized matrix deposition in 3D perfusion culture of marrow stromal osteoblasts in a dose-dependent manner. Proc Natl Acad Sci U S A. 2002;99(20):12600-5.

35. Datta N, P. Pham Q, Sharma U, Sikavitsas VI, Jansen JA, Mikos AG. In vitro generated extracellular matrix and fluid shear stress synergistically enhance 3D osteoblastic differentiation. Proc Natl Acad Sci U S A. 2006; 103(8):2488-93.

36. Sikavitsas VI, Bancroft GN, Holtorf HL, Jansen JA, Mikos AG. Mineralized matrix deposition by marrow stromal osteoblasts in 3D perfusion culture increases with increasing fluid shear forces. Proc Natl Acad Sci. 2003;100(25): 14683-8.

37. Grellier M, Bareille R, Bourget C, Amedee J. Responsiveness of human bone marrow stromal cells to shear stress. J Tissue Eng Regen Med. 2009;3(4):302-9.

38. Kapur S, Baylink DJ, William Lau KH. Fluid flow shear stress stimulates human osteoblast proliferation and differentiation through multiple 
interacting and competing signal transduction pathways. Bone. 2003; 32(3):241-51.

39. Kreke MR, Huckle WR, Goldstein AS. Fluid flow stimulates expression of osteopontin and bone sialoprotein by bone marrow stromal cells in a temporally dependent manner. Bone. 2005;36(6):1047-55.

40. Gemmiti CV, Guldberg RE. Fluid flow increases type II collagen deposition and tensile mechanical properties in bioreactor-grown tissue-engineered cartilage. Tissue Eng. 2006;12(3):469-79.

41. Bueno EM, Bilgen B, Barabino GA. Hydrodynamic Parameters Modulate Biochemical, Histological, and Mechanical Properties of Engineered Cartilage. Tissue Eng Part A. 2009;(4):773-85.

42. Vunjak-Novakovic G, Obradovic B, Martin I, Freed LE. Bioreactor studies of native and tissue engineered cartilage. Biorheology. 2002;39(1-2):259-68.

43. Yang YH, Barabino GA. Requirement for serum in medium supplemented with insulin-transferrin-selenium for hydrodynamic cultivation of engineered cartilage. Tissue Eng A. 2011;17(15-16):2025-35.

44. Engler AJ, Sen S, Sweeney HL, Discher DE. Matrix elasticity directs stem cell lineage specification. Cell. 2006;126(4):677-89.

45. Miyanishi K, Trindade MC, Lindsey DP, Beaupre GS, Carter DR, Goodman SB, et al. Effects of hydrostatic pressure and transforming growth factor-beta 3 on adult human mesenchymal stem cell chondrogenesis in vitro. Tissue Eng. 2006;12(6):1419-28.

46. Huang CYC, Hagar KL, Frost LE, Sun Y, Cheung HS. Effects of cyclic compressive loading on chondrogenesis of rabbit bone-marrow derived mesenchymal stem cells. Stem Cells. 2004;22(3):313-23.

47. Huang AH, Farrell MJ, Kim M, Mauck RL. Long-term dynamic loading improves the mechanical properties of chondrogenic mesenchymal stem cell-laden hydrogel. Eur Cell Mater. 2010;19:72-85.

48. Campbell JJ, Lee DA, Bader DL. Dynamic compressive strain influences chondrogenic gene expression in human mesenchymal stem cells. Biorheology. 2006;43(3):455-70.

49. Chisti Y. Hydrodynamic damage to animal cells. Crit Rev Biotechnol. 2001;21(2):67-110

50. Huang GY, Zhou LH, Zhang QC, Chen YM, Sun W, Xu F, et al. Microfluidic hydrogels for tissue engineering. Biofabrication. 2011;3(1):012001.

51. Johann RM, Renaud P. Microfluidic patterning of alginate hydrogels. Biointerphases. 2007;2(2):73-9.

52. Choi NW, Cabodi M, Held B, Gleghorn JP, Bonassar LJ, Stroock AD. Microfluidic scaffolds for tissue engineering. Nat Mater. 2007:6(11):908-15.

53. Khademhosseini A, Langer R, Borenstein J, Vacanti JP. Microscale technologies for tissue engineering and biology. Proc Natl Acad Sci U S A. 2006; 103(8):2480-7

\section{Submit your next manuscript to BioMed Central and we will help you at every step:}

- We accept pre-submission inquiries

- Our selector tool helps you to find the most relevant journal

- We provide round the clock customer support

- Convenient online submission

- Thorough peer review

- Inclusion in PubMed and all major indexing services

- Maximum visibility for your research

Submit your manuscript at www.biomedcentral.com/submit 